\title{
Caspase-mediated apoptosis in the vertebrate ovary
}

\author{
Alan L. Johnson and Jamie T. Bridgham \\ Department of Biological Sciences, University of Notre Dame, Notre Dame, IN 46556, USA
}

\begin{abstract}
In the vertebrate ovary, apoptosis is the process by which excess or non-viable germ and granulosa cells are eliminated early in ontogeny (often beginning before birth), and thereafter continuously throughout reproductive life. Accordingly, an excessively high rate or abnormal triggering of such cell death (and, by implication, follicle atresia) can negatively affect fertility. Programmed cell death involves the integration of many pathways and intracellular proteins, and central among these at almost every stage are members of the caspase family. Relatively little attention has been focused upon the ovary with regards to elucidating initiator and effector members of the caspase family, and pathways by which they are activated and inactivated. The present review briefly describes vertebrate caspases and the regulation of their function in non-ovarian tissues. Subsequently, the status of caspase expression and function in orchestrating apoptotic cell death in ovarian germ and follicle somatic cells is considered. The most compelling results implicating specific caspases in ovarian function have been derived from mouse single and double knockout model systems. The final outcome of continued studies, in addition to providing information regarding understanding and management of infertility, will influence the development of strategies to treat ovarian cancers and ameliorate the adverse effects of their therapy (for example, chemotherapy).
\end{abstract}

The developmentally regulated loss of female germ cells at various stages of pre- and post-natal development is considered a normal physiological process ensuring the greatest chance for ovulation of viable, fertilizable oocytes. However, abnormally high rates of attrition often result in subclinical or clinical infertility or the premature termination of fertility (for example, reproductive senescence or human menopause). Ovarian follicle atresia in all vertebrates studied to date is mediated via apoptosis, a process that can be initiated from within ovarian germ or follicle somatic cells, or in response to extrafollicular physiological (for example, cytokines) and pathological (for example, viral) signals. Caspases represent a family of intracellular cysteine proteases the actions of which are linked both to the initial and final stages of apoptosis in virtually all types of vertebrate cell. Moreover, recent studies have implicated additional intracellular factors in the mediation of the survival or death of vertebrate ovarian follicles. These factors include the $\mathrm{Bcl}-2$ family of death-inducing and -suppressing proteins, inhibitor of apoptosis proteins (IAPs), membrane-anchored and soluble receptors (for example, tumour necrosis factor receptor family, plus receptor-associated proteins) and cell signalling pathways (for example, adenylyl cyclase-cAMP, mitogenactivated protein kinase and phosphoinositol-3-kinase-Akt). Virtually all of these factors appear to interact with the caspase cascade of proteolytic activity.

Email: johnson.128@nd.edu

\section{Apoptosis mediated by caspases}

Apoptosis occurs in eukaryotes (including plants) and prokaryotes (Aravind et al., 1999). Genetic studies in the nematode Caenorhabditis elegans identified three fundamental components of the apoptotic pathway that are now known to be conserved in all eukaryotes (Miura and Yuan, 1996). Ced-9 is a negative regulator of apoptosis functionally related to the mammalian $\mathrm{Bcl}-2$ family of death-suppressing proteins. By contrast, Ced-3 is an orthologue from the family of mammalian caspases that acts as an effector of the cell-death pathway, whereas Ced-4 (which is orthologous to the mammalian apoptosis protease-activating factor-1, or Apaf-1) is a regulator of Ced-3-caspase activation. Loss of function mutations of either the ced-3 or ced-4 genes in C. elegans results in an abnormal increase in the number of germ cells, hyperplasia of the gonad and a subsequent decrease in the number of mature oocytes available for fertilization (Gumienny et al., 1999).

Apoptosis in vertebrate species involves well-organized morphological and biochemical processes characterized by membrane blebbing, cell shrinkage, DNA fragmentation (oligonucleosome formation), and the formation of membrane-enclosed vesicles (apoptotic bodies). A physiological consequence of apoptotic (compared with necrotic) cell death is the elimination of affected cells without the initiation of an inflammatory response. Apoptosis is a highly regulated process involving the sequential 


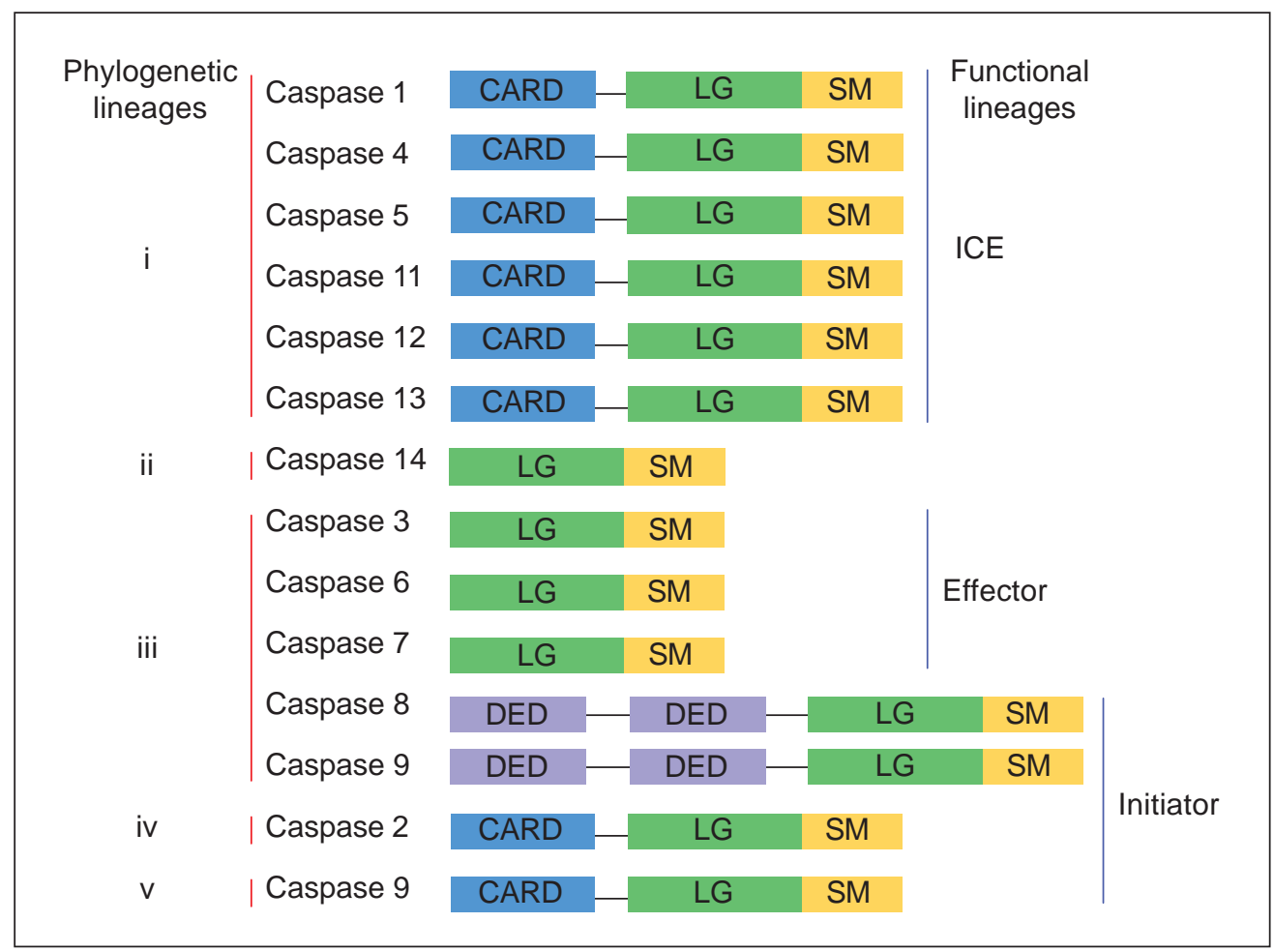

Fig. 1. Phylogenetic and functional relationships among members of the caspase family. Although phylogenetic analysis indicates five major lineages $(i-v)$ for the members of the family, caspases can be functionally grouped into interleukin-converting enzyme (ICE)-related members (associated primarily with cytokine activation), initiator capases (acting as transducers of extrinsic signals from death domaincontaining receptors, or of intrinsic mechanisms acting through mitochondria), and effector caspases (largely responsible for the downstream cleavage of functional cellular proteins). CARD: caspase recruitment domain; DED: death effector domain. Large (LG) and small (SM) subunit domains are processed to form the active caspase. The $\mathrm{N}$-terminal, variable length prodomain of each caspase is not depicted. Phylogenetic relatedness, as presented, is derived primarily from Wang and Gu (2001).

activation of multiple caspases, each of which cleaves target substrates at specific aspartic acid residues. A number of non-caspase proteases implicated in apoptosis (for example, granzyme B, cathepsins, calpains and the protease complex) have been reviewed elsewhere (Johnson, 2000) and will not be considered in this review.

\section{Vertebrate caspases}

The mammalian caspase family includes 14 members (caspases 1-14) (Hu et al., 1998; Humke et al. 1998; Wolf and Green, 1999) (Fig. 1). Several of these, including caspases 2, 3, 9, 11 and 12, have been implicated directly in mediating apoptosis within the ovary using genetic models (for examples, see Bergeron et al., 1998; Matikainen et al., 2001; Morita et al., 2001). Phylogenetic analysis of members of the caspase family has resulted in the classification of caspases into five lineages: (i) caspases 1, 4, 5, 11, 12 and 13 comprise the interleukin-1 $\beta$-converting enzyme (ICE), or caspase 1 subfamily (mainly involved in the processing of pro-inflammatory cytokines); (ii) caspase
14; (iii) caspases $3,6,7,8$ and 10 belong to the caspase 3 subfamily; (iv) caspase 2; and (v) caspase 9 (Wang and Gu, 2001).

All caspases are translated as inactive zymogens that contain a variable length prodomain and one or more heterodimerization modules, depending upon their function and position within the caspase cascade. For example, upstream initiator caspases such as caspases 8 and 10 contain two death effector domains (DED), whereas caspases 2 and 9 and ICE-related caspases contain a caspase recruitment domain (CARD), in addition to the proteolytic carboxyterminus. Binding of caspases to specific adaptor molecules via DED or CARD domains results in caspase autoactivation together with the activation of effector (or executioner) caspases. The functional carboxy-terminus of all caspases consists of large (for example, p20) and small (for example, p10) subunits that are cleaved at caspasespecific sites (the carboxy side of an aspartate residue) before activation. By comparison, downstream effector caspases contain only a variable length prodomain plus the functional carboxy-terminus domain. Processed subunits 
from two procaspase zymogens self-associate (to produce so-called homo-hetero dimers) and form two active enzyme sites at opposite ends of the complex (Earnshaw et al., 1999). Effector caspases cleave critical cellular proteins, such as nuclear lamins, cytoskeletal proteins, and the inhibitor of caspase-activated DNase, ICAD. For instance, cleavage of the ICAD permits activation of caspaseactivated DNase (CAD), the endonuclease responsible for oligonucleosome formation.

Six caspase orthologues have been at least partially characterized to date in Aves (chicken caspases 1, 2, 3, 6, 8 and 9), and each of these is expressed within the ovary (Johnson et al., 1997, 1998a; Johnson and Bridgham, 2000; S. Barton, J. T. Bridgham and A. L. Johnson, unpublished). (A recent search of a chicken Expressed Sequence Tag (EST) database indicates the presence of a caspase 7 orthologue (accession number AI981164).) Moreover, work with more distantly related vertebrate model systems, such as the zebrafish (Danio) and Xenopus, further establishes the high degree of caspase conservation among vertebrates and emphasizes the importance of an established cascade of caspase activity in cell death. There are at least six known caspase orthologues in Danio (Danio caspases 2, 3, 6, 8, 9 and 13; Inohara and Nunez, 2000), and Xenopus orthologues include caspases 1, 2, 3, 6, 8 and 10; Nakajima et al., 2000). Current efforts directed towards genome sequencing in each of a variety of non-mammalian species are predicted to find orthologues to most, if not all, of the remaining mammalian members of the caspase family.

\section{Caspase activation and cell death signalling}

Two general intracellular pathways involving initiator caspases that mediate apoptosis have so far been identified. One upstream pathway promoted by the activation of several members of the tumour necrosis factor receptor (TNF-R) family that contain an intracellular death domain (DD) results in the processing of the initiator caspases, caspases 8 or 10, or both (Fig. 2). For instance, Fas-induced cell death is mediated by the recruitment and activation of caspase 8 via the Fas adaptor protein, Fas-associated death domain (FADD; Strasser and Newton, 1999). Whereas a FADD death domain is required for association with the death receptor to form the death-inducing signal complex (DISC), a FADD death effector domain (DED) is critical for the recruitment of caspase 8 . Conversely, inhibition of such death receptor-induced activation may be affected by a FADD-like ICE inhibitory protein (FLIP), which competitively blocks the processing of the procaspase at the DISC (Budihardjo et al., 1999). The overall importance of FLIP expression in attenuating apoptotic cell death is suggested by the finding that FLIP $-/$ - mouse embryos fail to survive past day 10.5 (Yeh et al., 2000).

An alternative upstream pathway involving an initiator caspase occurs after a perturbation of the mitochondria (for example, one induced by chemotherapeutic drugs, oxidative stress or DNA damage), which promotes the release of mitochondrial cytochrome $\mathrm{C}$ and the intermembrane protein DIABLO-Smac to the cytosol (Ekert et al., 2001). Cytosolic cytochrome $\mathrm{C}$ mediates the formation of a high molecular weight complex consisting of Apaf-1 and caspase 9 (the apoptosome complex), and the subsequent processing of caspase 9, whereas a primary action of DIABLO-Smac is to inactivate IAPs. Autoactivation of either caspase 8 or caspase 9 eventually initiates the processing of an effector caspase such as caspase 3,6 or 7, and the full potentiation of the caspase cascade.

Not unexpectedly, caspase activation and activity is regulated tightly by a variety of cellular pro- and antiapoptotic proteins, including members of the Bcl-2-related family and IAPs. Given the abundance of information derived from both primary and transformed cell lines, only a few pertinent examples will be provided here (for more complete reviews, see Schendel et al., 1998; Miller, 1999). Anti-apoptotic members of the Bcl-2 family, such as Bcl-2 and $\mathrm{BCl}-\mathrm{xL}$ ong, consist of four $\mathrm{BCl}-2$ homology $(\mathrm{BH})$ domains $(\mathrm{BH} 1-4)$ plus a transmembrane region for anchoring to mitochondria. It has been proposed that such proteins form ion channels within the mitochondrial membrane, and help maintain mitochondrial integrity by allowing the export of $\mathrm{H}^{+}$ions from the inner mitochondrial space. Overexpression of $\mathrm{Bcl}-2$ can inhibit agonist (for example, resveratrol)-induced apoptosis by preventing cytochrome $\mathrm{C}$ release and caspase 9 activation (Park et al., 2001). Similarly, staurosporine-induced caspase 9-like activity and the progression of apoptosis is attenuated by chicken Bcl-xLong (Fig. 3). Such results clearly place antiapoptotic proteins of the Bcl-2 family upstream of caspase activation.

Pro-apoptotic Bcl-2-related proteins, such as Bid, Bad, Bik and Bim, contain a single $\mathrm{BH} 3$ domain and are capable of counteracting the cytoprotective effects of anti-apoptotic $\mathrm{BCl}-2$ and $\mathrm{BCl}-\mathrm{xL}$ Long by forming heterodimers. For instance, Fas receptor-activated caspase 8 mediates cleavage of Bid, and the resulting truncated Bid proceeds to neutralize the antiapoptotic activity of $\mathrm{BCl}-2$ or $\mathrm{Bcl}-x$ Long. However, proapoptotic Bax lacks a $\mathrm{BH} 4$ domain but maintains the ability to form ion channels within the mitochondrial membrane. After cellular DNA damage, Bax can heterodimerize with and antagonize the anti-apoptotic effects of $\mathrm{BCl}-2$ or directly promote the release of cytochrome $c$ and DIABLO-Smac (Fig. 2).

Vertebrate IAPs directly bind to and potently inhibit caspase activation and activity (Deveraux and Reed, 1999). The second in the series of three baculovirus IAP repeat (BIR) domains derived from X-Linked IAP (XIAP or MIHA) is both necessary and sufficient to suppress caspase 3 and caspase 7 activity, while the third BIR domain of XIAP-MIHA combined with the adjacent zinc-binding RING domain interacts with and inhibits caspase 9 (Deveraux et al., 1999). Significantly, the inhibitory actions of XIAP-MIHA can be blocked after the release of mitochondrial DIABLO-Smac, which preferentially binds XIAP-MIHA and thus facilitates activation of caspase 9 (Ekert et al., 2001). 


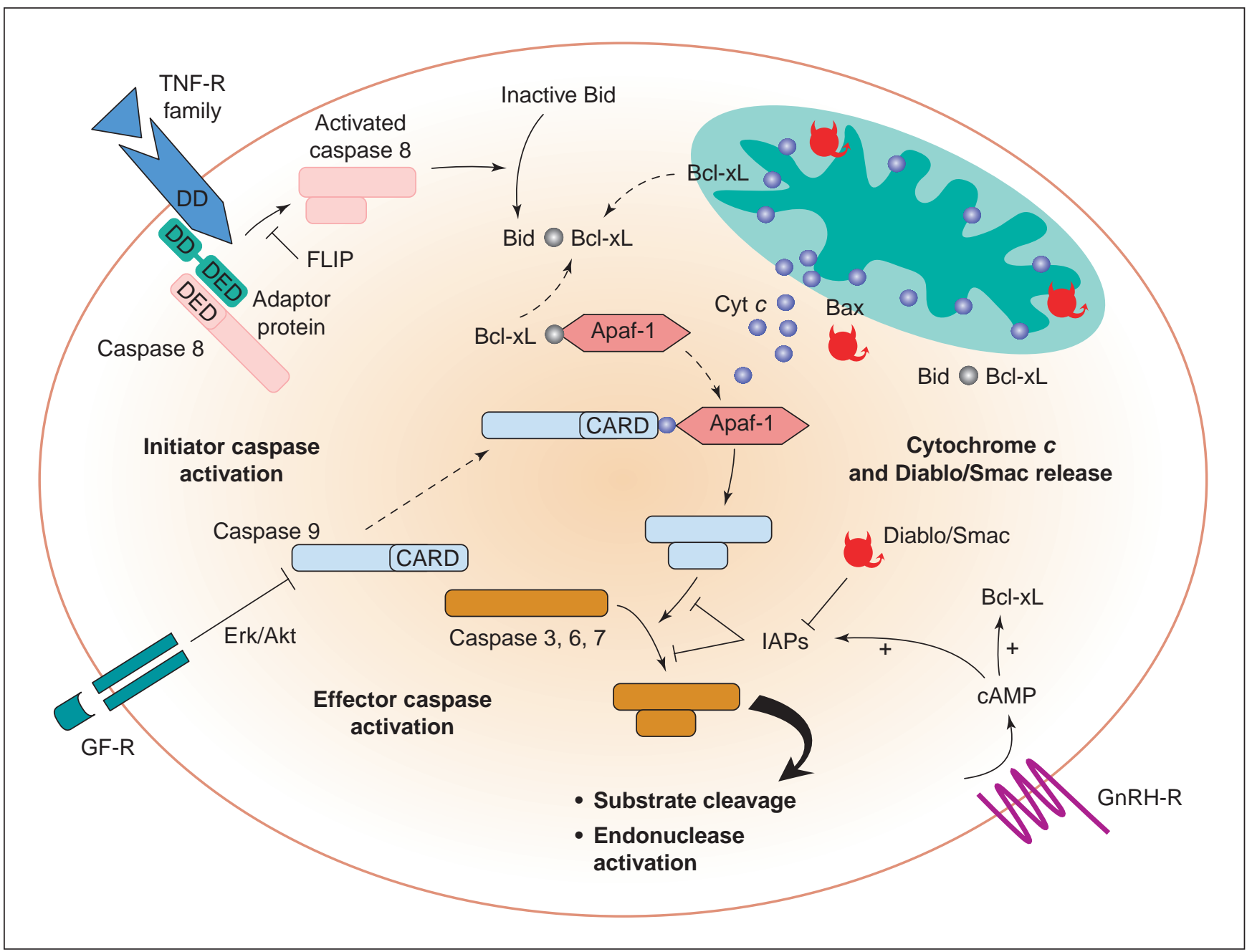

Fig. 2. Representative pathways leading to initiator caspase activation in the ovary include death domain (DD)-containing receptors from the tumour necrosis factor receptor (TNF-R) family plus a variety of intrinsic and extrinsic factors that can promote the release of mitochondrial cytochrome $c$ (Cyt $c$ ) and Diablo-Smac. Receptor activation of the initiator caspase, caspase 8, occurs via an adaptor protein containing both a DD and a death effector domain (DED). Activation of caspase 8 can result in the direct activation of an effector caspase (not shown) or actions at the mitochondria. Bid and Bax represent pro-apoptotic proteins, and Bcl-xL represents one of several potential anti-apoptotic proteins. In granulosa cells, Bcl-xL may, on the basis of its patterns of expression and upregulation via gonadotrophin receptor $(\mathrm{GnRH}-\mathrm{R})$ activation, represent one of the more important Bcl-2-related anti-apoptotic proteins. Although granulosa cell survival promoted by growth factor receptor (GF-R) activation is mediated via MAP kinase-Erk and PI-3-kinase-Akt signalling, the downstream mechanisms largely remain to be determined. Apaf-1: apoptosis protease-activating factor-1; CARD: caspase recruitment domain; FLIP: FADD-like interleukin-1 $\beta$-converting enzyme (ICE) inhibitory protein; IAPs: inhibitor of apoptosis proteins.

Receptor-mediated cell signalling pathways, including mitogen-activated protein (MAP) kinase and phosphoinositol3-kinase-Akt, can attenuate or promote caspase-dependent apoptosis, depending upon the type of cell. Growth factor (for example, epidermal growth factor or insulin-like growth factor I)-induced activation of the phosphoinositol3-kinase-Akt cell survival pathway inhibits caspase 9 activation and activity directly, presumably via a phosphorylation event (Cardone et al., 1998), and signalling via Akt prevents serum withdrawal-induced apoptosis in cultured hen granulosa cells (Johnson et al., 2001). Conversely, downstream effector caspases, such as caspases
3 and 7, target the epidermal growth factor receptor (EGFR) presumably to reduce further cell survival signalling (Bae et al., 2001).

Collectively, the selective examples above illustrate the complexity and redundancy of the pro- and anti-apoptotic regulatory mechanisms that ultimately determine the status of cellular caspase activity. Given that the myriad of cell signalling pathways and cellular proteins that ultimately balance cell viability and cell death is largely specific to the type of cell, the next section of this review specifically addresses current understanding of these processes within the ovary. 


\section{Caspases in the vertebrate ovary}

Evidence for the involvement of caspases in regulating ovarian germ cell viability

During embryonic development, the female ovary is endowed with considerably more germ cells than are present at puberty. This excessive number of germ cells is reduced by two-thirds or more via the process of apoptosis during the late embryonic-early postpartum stage (Morita and Tilly, 1999). Targeted caspase 2 gene inactivation in mouse embryonic stem cells results in a marked decrease in this development-related germ cell death, and consequently, a significantly greater number of primordial follicles within the postnatal ovary compared with the number of follicles in wild-type controls. Moreover, the absence of caspase 2 activity renders germ cells largely resistant to chemotherapeutic drug (doxorubicin)-induced apoptosis (Bergeron et al., 1998).

Studies with caspase 11-deficient mice showed that females are born with a severe depletion of germ cells (Morita et al., 2001). In light of considerable previous data implicating caspase 11 as a functional mediator of cytokine processing (Fig. 1; Earnshaw et al., 1999), it was reasoned that the absence of caspase 11 activity results in a deficiency of fully processed cell survival cytokines within developing oocytes. In fact, a significantly greater proportion of fetal ovarian germ cells derived from caspase 11 -deficient mice and cultured in the presence of interleukin $1 \alpha($ IL- $\alpha)$ or IL-1 $\beta$ survived than did those cultured in the absence of these cytokines. Further experiments with caspase 11-caspase 2 double mutants determined that the germ cell loss observed in caspase 11deficient females was dependent upon functional caspase 2 activity. These results lead to the conclusion that cytokines processed as a result of caspase 11 activity (including, but not necessarily limited to, IL-1 $\alpha$ and IL-1 $\beta$ ) suppress downstream effector caspases such as caspase 2 .

Prenatal germ cells in cultured ovaries from caspase 9-/mice are more resistant to apoptosis induced by cytokine deprivation than are those from wild-type controls (Maravei et al., 2001), whereas cumulus-denuded oocytes from mature caspase 12 -/- mice are comparatively more resistant to the chemotherapeutic drug doxorubicin (Perez et al., 2001). Although both these reports provide intriguing evidence for the involvement of caspases 9 and 12 in the regulation of the number of germ cells, the physiological significance in vivo and the precise mechanisms of activation in the ovary remain to be elucidated.

In contrast, caspase 3 activity is apparently not essential for either development-related or chemotherapeutic (for example, doxorubicin)-induced germ cell apoptosis at day 4 after birth, as determined from studies using caspase 3 gene knockout mice (Matikainen et al., 2001). In light of evidence that additional effector phase members of the caspase family are expressed within the oocyte (for example, caspases 6 and 7; Exley et al., 1999), it is likely that redundant effector caspases function to ensure the

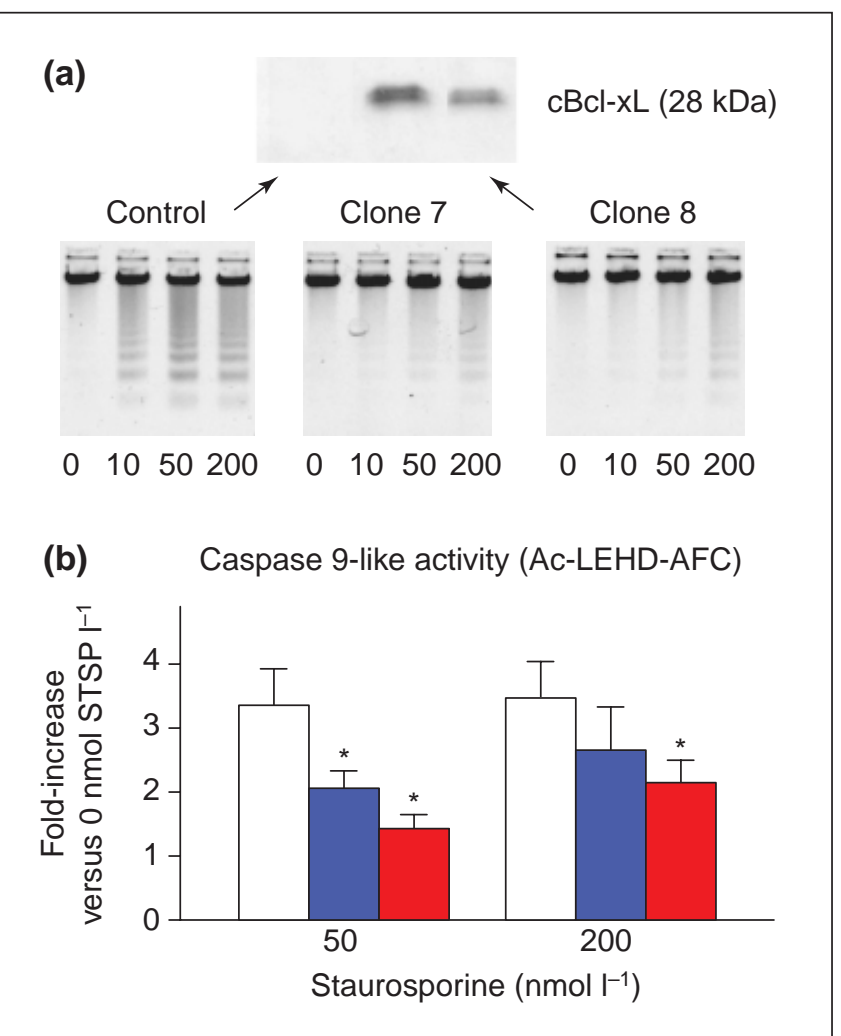

Fig. 3. Overexpression of chicken $\mathrm{Bcl}-\mathrm{xL}$ Long $(\mathrm{BCl}-\mathrm{xL})$ in Chinese hamster ovary $(\mathrm{CHO})$ cells attenuates caspase 9-like activity and the progression of apoptosis in staurosporine-treated cells. (a) $\mathrm{CHO}$ cells were transfected with chicken $\mathrm{BCl}-\mathrm{xL}$ and clonally selected for stable expression. (b) Cultured cells were treated with 0-200 nmol staurosporine $\mathrm{I}^{-1}$ for $18 \mathrm{~h}$, then collected for evaluation of oligonucleosome formation or assayed for caspase 9-like activity using the fluorogenic substrate Ac-LEHD-AFC. White bar: CHOControl; blue bar: $\mathrm{CHO}-$ clone number 7; red bar: $\mathrm{CHO}$-clone number 8 . *Significant attenuation of in vitro caspase activity compared with the control cells $(P<0.05)$.

completion of apoptosis. In addition to functional studies of caspases 2, 3, 9 and 11 in pre- and early postnatal oocytes, RT-PCR studies have detected expression of caspases 1, 6 and 7 within oocytes from superovulated mice (Exley et al., 1999); however, the activity and function of each caspase within mature oocytes has yet to be established.

Future genetic model systems designed to evaluate the role of additional caspases will likely require the use of conditional knockout model systems (Pru and Tilly, 2001), as some caspase knockout models (for example, those for caspases 7 and 8) have proven to be lethal to embryos (Zheng et al., 1999). Nevertheless, results from the various caspase-deficient model systems generated to date have initiated the elucidation of the germ cell-specific pathways (compared with the ovarian somatic cell-specific pathways; Fig. 4) responsible for mediating apoptosis both before and after birth. 


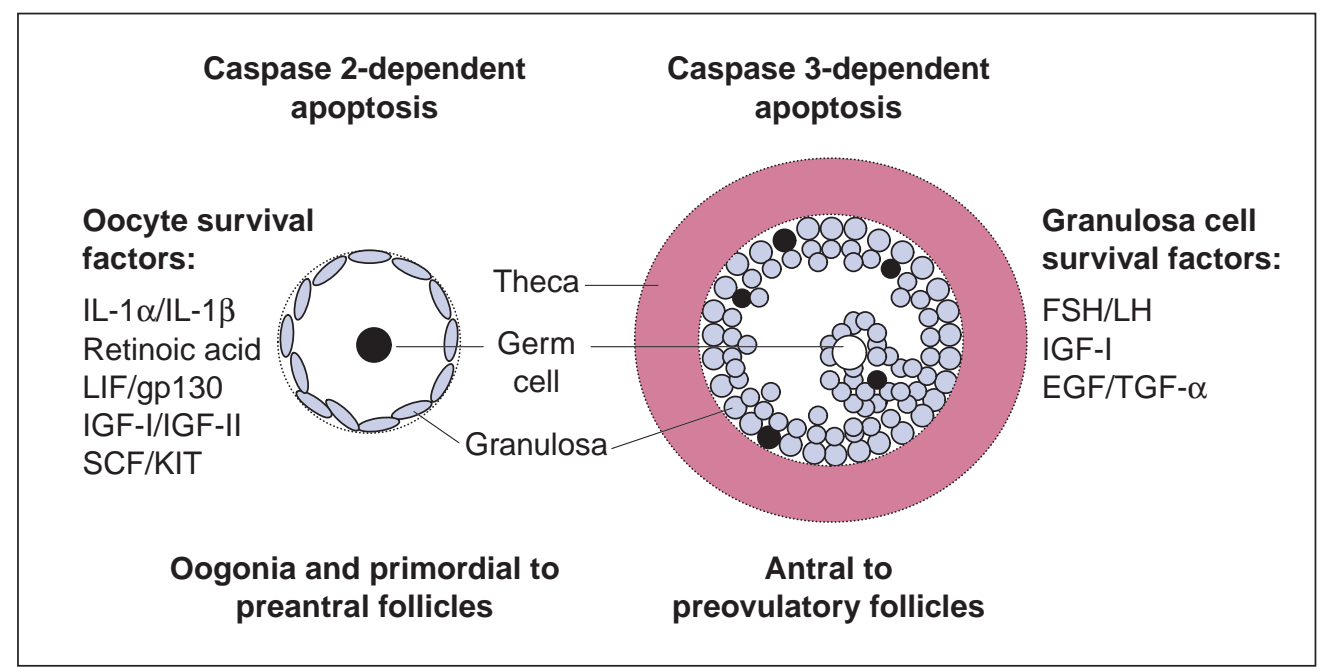

Fig. 4. Cell survival factors and caspase-mediated cell death in the ovary differ with respect to type of cell. Apoptosis initiated within oogonia and oocytes from primordial to preantral follicles is caspase 2dependent and can be attenuated by cell survival factors such as interleukin-1 $\alpha$ (IL-1 $\alpha)$ and IL-1 $\beta$, retinoic acid, leukaemia inhibiting factor (LIF) via its receptor gp130, insulin-like growth factor I (IGF-I) and IGF-II, and stem cell factor (SCF) via its receptor KIT. The death of the oocyte leads ultimately to granulosa cell death and follicle atresia. In contrast, caspase 3-dependent apoptosis within the granulosa cell layer is a frequent cause of follicle atresia during the antral to tertiary (preovulatory) stages of development. Dark circles represent apoptotic germ or somatic cells. Autocrine and paracrine factors known to promote granulosa survival include LH, FSH, IGF-I, epidermal growth factor (EGF) and transforming growth factor $\alpha$ (TGF- $\alpha$ ).

\section{Mediation of follicle atresia by caspases}

During the postnatal development of primordial through to preantral mammalian follicles, atresia is initiated mainly by the death of the oocyte (Morita and Tilly, 1999). Germ cell apoptosis may result from either the absence or insufficient availability of cell survival factors (for example, ILs, stem cell factor, leukaemia inhibitory factor and insulinlike growth factor I; Morita and Tilly, 1999), environmental toxins or chemotherapeutics (Robles et al., 2000). The loss of germ cell viability results in the death of the adjacent somatic cell layer via apoptosis (Fig. 4). In contrast, atresia in preantral through to preovulatory follicles is frequently characterized by the rapid progression of apoptosis throughout the granulosa layer, which leads ultimately to the demise of the oocyte (Morita and Tilly, 1999; Tilly, 2001).

Granulosa cells from healthy follicles possess almost exclusively the inactive (unprocessed) form of caspase 3, whereas granulosa cells from atretic follicles demonstrate increased concentrations of activated caspase 3 . The active processing of caspase 3 is associated with the cleavage of poly-(ADP-ribose)-polymerase (PARP) and actin, and the formation of oligonucleosomes (Boone and Tsang, 1998). Unlike the progression in germ cells, the normal progression of apoptosis in granulosa cells from preantral to preovulatory follicles is dependent upon the activity of caspases 3 and 7 , as determined from studies using caspase 3 knockout mice (Matikainen et al., 2001). This finding reinforces the specificity of cell lineage-dependent apoptotic pathways, and provides for specificity in the paracrine-autocrine signals that initiate germ cell versus somatic cell death.

Moreover, ovaries from caspase 9-deficient mice contain numerous developing follicles that fail to complete atresia owing to an apparent failure of granulosa cell apoptosis (Maravei et al., 2001). Indirect evidence indicates a role for caspase 9 as an initiator of caspase 3 activity, as Apaf-1 expression in antral follicles is suppressed by gonadotrophin (equine chorionic gonadotrophin) priming (Robles et al., 1999). Angelastro et al. (2001) have reported ovarian expression of a caspase 9 variant containing a unique carboxy-terminus (caspase 9-carboxy-terminaldivergent) that may act as a dominant-negative isoform, but it remains to be established to what extent this alternatively spliced variant functions to modify the progression of apoptosis within the ovary under physiological conditions.

Although pathways mediating death receptor-induced caspase activation have received less attention, there is evidence for both expression and activity of caspase 8 (but not caspase 10) in granulosa cells (Hu et al., 2001; S. Barton, J. T. Bridgham and A. L. Johnson, unpublished). Finally, evidence for direct involvement of caspase 1 in granulosa cell apoptosis is less convincing, as the amounts of mRNA transcript encoding caspase 1 compared with 
mRNA transcript encoding caspase 3 are extremely low, and IL-1 $\beta$ fails to attenuate the progression of apoptosis in hen granulosa cells (Johnson et al., 1998a).

In addition, various IAPs are expressed within ovarian granulosa cells (clAP1: Johnson et al., 1998b; Li et al., 1998; XIAP: Asselin et al., 2001; survivin, Fig. 5). Nevertheless, much work remains to be done to establish the site of inhibitory action for each IAP within the caspase cascade.

Several intracellular signalling pathways have been linked directly to promoting granulosa cell survival, including pathways involving gonadotrophin- and vasoactive intestinal peptide-induced cAMP formation (Flaws et al., 1995; Johnson et al., 1999), mitogen-activated protein (MAP) kinase-Erk (Gebauer et al., 1999) and phosphoinositol-3kinase-Akt (Westfall et al., 2000; Asselin et al., 2001; Johnson et al., 2001). For instance, signalling via cAMP probably enhances resistance of hen granulosa cells to apoptosis, at least in part, by increasing expression of the anti-apoptotic proteins Bcl-xLong and CIAP1.

\section{Caspase-mediated regression of the corpus luteum-postovulatory follicle}

After an infertile ovulatory cycle in a female mammal, regression of the corpus luteum is a prerequisite to the initiation of a new wave of follicle development. There has been relatively little work directed towards elucidating caspase-dependent pathways involved in corpus luteum regression. As might be predicted, a number of initiator and effector caspases expressed within preovulatory follicles have also been identified within the corpus luteum, including caspases 1, 3 and 9 (Krajewska et al., 1997; Rueda et al., 1999; Khan et al., 2000). In non-primate species, $\mathrm{PGF}_{2 \alpha}$ derived from the uterus is considered a primary initiator of luteal regression. $\mathrm{PGF}_{2 \alpha}$-induced apoptosis within the ovine corpus luteum is associated with both increased mRNA expression and activity of caspase 3 (Rueda et al., 1999). The actions of $\mathrm{PGF}_{2 \alpha}$ may occur, at least in part, as a result of protein kinase C-mediated production of reactive oxygen species (ROS) (Nakamura and Sakamoto, 2001). Moreover, in cows, increased concentrations of the caspase 1 transcript in the corpus luteum occur coincident with the onset of luteolysis (Rueda et al., 1997). Although caspase 1 activity is associated primarily with the processing of proinflammatory cytokines, it is not yet clear whether this association is involved in the initiation or potentiation of luteal regression.

From an evolutionary perspective, ovulated follicles from avian species rapidly terminate the biosynthesis of progesterone and fail to form a functional corpus luteum. Instead, the residual postovulatory follicle begins to regress via caspase-mediated apoptosis shortly after ovulation (Fig. 6), and is almost entirely resorbed within 4-6 days after ovulation. No studies have thus far been reported that define the signals and initiator pathways responsible for regression of the postovulatory follicle. (a)

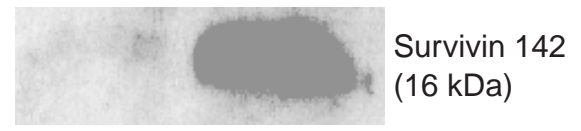

(b)

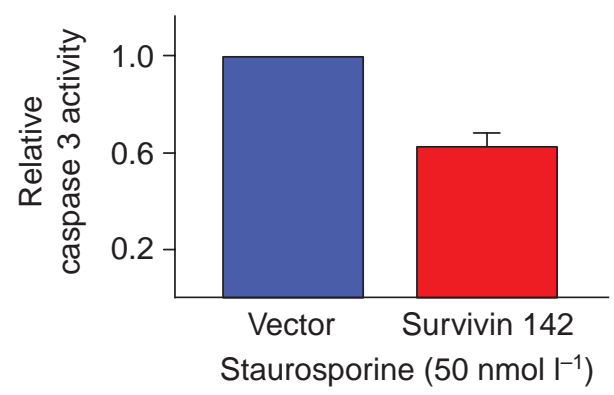

Fig. 5. Transient transfection of cultured hen granulosa cells with the inhibitor of apoptosis protein chicken survivin 142 attenuates caspase 3 activity induced by treatment with staurosporine (A. L. Johnson, J. Langer and J. T. Bridgham, unpublished). (a) Representative western blot hybridization of the overexpressed chicken survivin 142 protein $36 \mathrm{~h}$ after transfection. (b) Caspase 3 activity (measured using the fluorogenic substrate, Ac-DEVD-AFC) determined from a cell-free caspase 3 activity assay (Johnson and Bridgham, 2000).

(a)

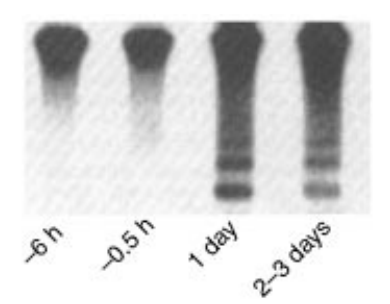

(b)

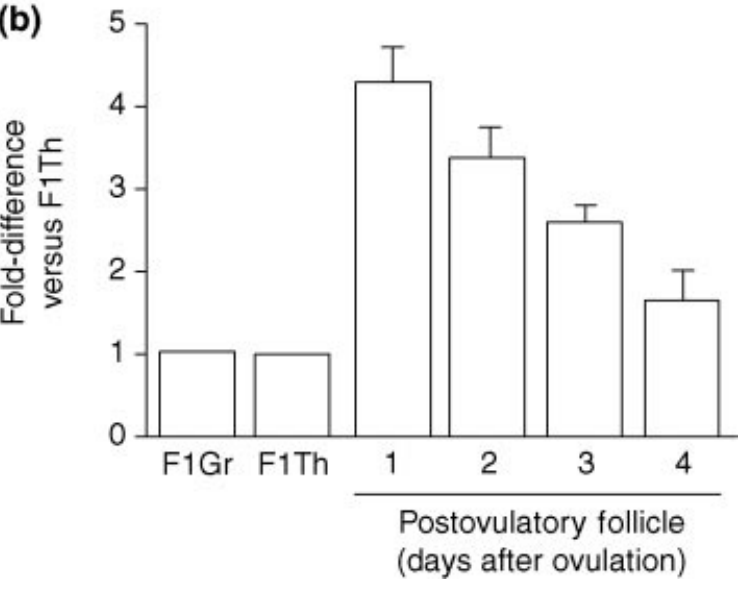

Fig. 6. (a) Rapid regression of the chicken postovulatory follicle 1-3 days after ovulation is reflected by oligonucleosome formation (hours before or days after ovulation) and (b) expression of caspase 3 activity. Caspase activity in whole postovulatory follicles is compared with activity within the largest preovulatory follicle theca (F1Th) and granulosa (F1Gr) layers collected approximately $17 \mathrm{~h}$ before ovulation. 


\section{Conclusions}

Although there has been considerable recent progress in defining the caspases involved in regulating the number of germ cells and follicle atresia, and the differences in the involvement of specific caspases in ovarian cell lineage in vertebrate species, there is clearly more to be learned. Further progress in this area will be complicated by the presence of multiple, and potentially redundant, caspase cascades that mediate apoptosis, together with the multiple checks and balances provided by various pro- and antiapoptotic signalling pathways and cellular regulatory proteins expressed within the ovary. Nevertheless, such progress will no doubt impact positively upon the diagnosis and treatment of clinical infertility, the development of strategies to prevent chemotherapy-induced infertility, and the understanding of normal and pathological processes leading to reproductive senescence.

Note added in proof: a recent publication* has documented in caspase 3 null mice the functional requirement for caspase 3 activity in the morphological regression of the corpus luteum after a non-fertile ovulation.

*Carambula SF, Matikainen T, Lynch MP, Flavell RA, Goncalves PBD, Tilly JL and Rveda BR (2002) Caspase-3 is a pivotal mediator of apoptosis during regression of the ovarian corpus luteum Endocrinology 143 1495-1505

The authors thank J. Martin, J. Langer and S. Barton for their contributions towards providing unpublished data discussed within this review. Recent related work within the authors' laboratory has been supported by grants from the NSF (IBN9419613), USDA (99-35203-7736) and the NIH (HD36095).

\section{References}

Key references are identified by asterisks.

Angelastro JM, Moon NY, Liu DX, Yang AS, Greene LA and Franke TF (2001) Characterization of a novel isoform of caspase-9 that inhibits apoptosis Journal of Biological Chemistry 276 12 190-12 200

Aravind L, Dixit VM and Koonin EV (1999) The domains of death: evolution of the apoptosis machinery Trends in Biochemical Science 24 47-53

Asselin E, Wang Y and Tsang BK (2001) X-linked inhibitor of apoptosis protein activates the phosphatidylinositol 3-kinase/Akt pathway in rat granulosa cells during follicular development Endocrinology 142 2451-2457

Bae SS, Choi JH, Oh YS, Perry DK, Ryu SH and Suh PG (2001) Proteolytic cleavage of epidermal growth factor receptor by caspases FEBS Letters 491 16-20

Bergeron L, Perez GI, Macdonald G et al. (1998) Defects in regulation of apoptosis in caspase-2-deficient mice Genes and Development 12 1304-1314

Boone DL and Tsang BK (1998) Caspase-3 in the rat ovary: localization and possible role in follicular atresia and luteal regression Biology of Reproduction 58 1533-1539

Budihardjo I, Oliver H, Lutter M, Luo X and Wang X (1999) Biochemical pathways of caspase activation during apoptosis Annual Reviews in Cell and Developmental Biology 15 269-290

Cardone MH, Roy N, Stennicke HR, Salvesen GS, Franke TF, Stanbridge E, Frisch S and Reed JC (1998) Regulation of cell death protease caspase-9 by phosphorylation Science $\mathbf{2 8 2} 1318-1321$

Deveraux QL and Reed JC (1999) IAP family proteins - suppressors of apoptosis Genes and Development 13 239-252
Deveraux QL, Leo E, Stennicke HR, Welsh K, Salvesen GS and Reed JC (1999) Cleavage of human inhibitor of apoptosis protein XIAP results in fragments with distinct specificities for caspases EMBO Journal $\mathbf{1 8}$ $5242-5251$

*Earnshaw WC, Martins LM and Kaufmann SH (1999) Mammalian caspases: structure, activation, substrates, and functions during apoptosis Annual Reviews in Biochemistry 68 383-424

Ekert PG, Silke J, Hawkins CJ, Verhagen AM and Vaux DL (2001) DIABLO promotes apoptosis by removing MIHA/XIAP from processed caspase 9 Journal of Cell Biology 152 483-490

Exley GE, Tang C, McElhinny AS and Warner CM (1999) Expression of caspase and BCL-2 apoptotic family members in mouse preimplantation embryos Biology of Reproduction 61 231-239

Flaws JA, DeSanti A, Tilly KI, Javid RO, Kugu K, Johnson AL, Hirshfield AN and Tilly JL (1995) Vasoactive intestinal peptide-mediated suppression of apoptosis in the ovary: potential mechanisms of action and evidence of a conserved antiatretogenic role through evolution Endocrinology $1364351-4359$

Gebauer G, Peter AT, Onesime D and Dhanasekaran N (1999) Apoptosis of ovarian granulosa cells: correlation with the reduced activity of ERKsignaling module Journal of Cellular Biochemistry 75 547-554

Gumienny TL, Lambie E, Hartwieg E, Horvitz HR and Hengartner MO (1999) Genetic control of programmed cell death in the Caenorhabditis elegans hermaphrodite germline Development 126 1011-1022

Hu S, Snipas SJ, Vincenz C, Salvesen G and Dixit VM (1998) Caspase-14 is a novel developmentally regulated protease Journal of Biological Chemistry 273 29648-29653

Hu X, Christian PJ, Thompson KE, Sipes IG and Hoyer PB (2001) Apoptosis induced in rats by 4 -vinylcyclohexene diepoxide is associated with activation of the caspase cascades Biology of Reproduction 65 87-93

Humke EW, Ni J and Dixit VM (1998) ERICE, a novel FLICE-activatable caspase Journal of Biological Chemistry 273 15 702-15 707

Inohara N and Nunez G (2000) Genes with homology to mammalian apoptosis regulators identified in zebrafish Cell Death and Differentiation 7 509-510

Johnson DE (2000) Noncaspase proteases in apoptosis Leukemia 14 1695-1703

Johnson AL and Bridgham JT (2000) Caspase-3 and -6 expression and enzyme activity in hen granulosa cells Biology of Reproduction $\mathbf{6 2}$ 589-598

Johnson AL, Bridgham JT, Bergeron L and Yuan J (1997) Characterization of the avian Ich-1 CDNA and expression of Ich-1L mRNA in the hen ovary Gene 192 227-233

Johnson AL, Bridgham JT, Munks M and Witty JP (1998a) Characterization of the chicken interleukin-1 beta converting enzyme (caspase-1) cDNA and expression of caspase-1 mRNA in the hen Gene 219 55-62

Johnson AL, Bridgham JT, Digby MR and Lowenthal JW (1998b) Expression of the inhibitor of T-cell apoptosis (ita) gene in hen ovarian follicles during development Biology of Reproduction 58 414-420

Johnson AL, Bridgham JT and Jensen T (1999) Bcl-X(LONG) protein expression and phosphorylation in granulosa cells Endocrinology $\mathbf{1 4 0}$ $4521-4529$

Johnson AL, Bridgham JT and Swenson JA (2001) Activation of the Akt/protein kinase B signaling pathway is associated with granulosa cell survival Biology of Reproduction 64 1566-1574

Khan SM, Dauffenbach LM and Yeh J (2000) Mitochondria and caspases in induced apoptosis in human luteinized granulosa cells Biochemical and Biophysical Research Communications 269 542-545

Krajewska M, Wang HG, Krajewski S, Zapata JM, Shabaik A, Gascoyne R and Reed JC (1997) Immunohistochemical analysis of in vivo patterns of expression of CPP32 (Caspase-3), a cell death protease Cancer Research 57 1605-1613

Li J, Kim JM, Liston P, Li M, Miyazaki T, Mackenzie AE, Korneluk RG and Tsang BK (1998) Expression of inhibitor of apoptosis proteins (IAPs) in rat granulosa cells during ovarian follicular development and atresia Endocrinology 139 1321-1328

Maravei DV, Morita Y, Kuida K and Tilly JL (2001) Pre- and postnatal ovarian apoptosis defects in caspase-9-deficient mice Endocrine Society Annual Meeting, 2001 Abstract 2037 
*Matikainen T, Perez GI, Zheng TS, Kluzak TR, Rueda BR, Flavell RA and Tilly JL (2001) Caspase-3 gene knockout defines cell lineage specificity for programmed cell death signaling in the ovary Endocrinology 142 2468-2480

Miller LK (1999) An exegesis of IAPs: salvation and surprises from BIR motifs Trends in Cell Biology 9 323-328

* Miura M and Yuan J (1996) Mechanisms of programmed cell death in Caenorhabditis elegans and vertebrates Current Topics in Developmental Biology 32 139-174

*Morita Y and Tilly JL (1999) Oocyte apoptosis: like sand through an hourglass Developmental Biology 213 1-17

Morita Y, Maravei DV, Bergeron L et al. (2001) Caspase-2 deficiency prevents programmed germ cell death resulting from cytokine insufficiency but not meiotic defects caused by loss of ataxiatelangiectasia-mutated (Atm) gene function Cell Death and Differentiation 8 614-620

Nakajima K, Takahashi A and Yaoita Y (2000) Structure, expression, and function of the Xenopus laevis caspase family Journal of Biological Chemistry $27510484-10491$

Nakamura T and Sakamoto K (2001) Reactive oxygen species up-regulates cyclooxygenase-2, p53, and Bax mRNA expression in bovine luteal cells Biochemical and Biophysical Research Communications 284 203-210

Park JW, Choi YJ, Suh SI et al. (2001) Bcl-2 overexpression attenuates resveratrol-induced apoptosis in $U 937$ cells by inhibition of caspase-3 activity Carcinogenesis 22 1633-1639

Perez GI, Nakagawa T, Trbovich AM, Yuan J and Tilly JL (2001) Involvement of caspase-12 in doxorubicin-induced oocyte apoptosis Journal for the Society of Gynecological Investigations 8 (Supplement) Abstract 767

Pru JK and Tilly JL (2001) Programmed cell death in the ovary: insights and future prospects using genetic technologies Molecular Endocrinology 15 845-853

Robles R, Tao XJ, Trbovich AM, Maravel DV, Nahum R, Perez GI, Tilly KI and and Tilly JL (1999) Localization, regulation and possible consequences of apoptotic protease-activating factor-1 (Apaf-1) expression in granulosa cells of the mouse ovary Endocrinology 140 2641-2644
Robles R, Morita Y, Mann KK, Perez GI, Yang S, Matikainen T, Sherr DH and Tilly JL (2000) The aryl hydrocarbon receptor, a basic helix-loop-helix transcription factor of the PAS gene family, is required for normal ovarian germ cell dynamics in the mouse Endocrinology 141 450-453

Rueda BR, Tilly KI, Botros IW, Jolly PD, Hansen TR, Hoyer PB and Tilly JL (1997) Increased bax and interleukin-1beta-converting enzyme messenger ribonucleic acid levels coincide with apoptosis in the bovine corpus luteum during structural regression Biology of Reproduction 56 186-193

Rueda BR, Hendry IR, Tilly JL and Hamernik DL (1999) Accumulation of caspase-3 messenger ribonucleic acid and induction of caspase activity in the ovine corpus luteum following prostaglandin F2alpha treatment in vivo. Biology of Reproduction 60 1087-1092

Schendel SL, Montal M and Reed JC (1998) BCl-2 family proteins as ionchannels Cell Death and Differentiation 5 372-380

Strasser A and Newton K (1999) FADD/MORT1, a signal transducer that can promote cell death or cell growth International Journal of Biochemistry and Cell Biology 31 533-537

*Tilly JL (2001) Commuting the death sentence: how oocytes strive to survive Nature Reviews, Molecular and Cellular Biology 2 838-848

Wang Y and Gu X (2001) Functional divergence in the caspase gene family and altered functional constraints statistical analysis and prediction Genetics 158 1311-1320

Westfall SD, Hendry IR, Obholz KL, Rueda BR and Davis JS (2000) Putative role of the phosphatidylinositol 3-kinase-Akt signaling pathway in the survival of granulosa cells Endocrine 12 315-321

Wolf BB and Green DR (1999) Suicidal tendencies: apoptotic cell death by caspase family proteinases Journal of Biological Chemistry 274 20049-20052

Yeh WC, Itie A, Elia AJ et al. (2000) Requirement for Casper (c-FLIP) in regulation of death receptor-induced apoptosis and embryonic development Immunity 12 633-642

Zheng TS, Hunot S, Kuida K and Flavell RA (1999) Caspase knockouts: matters of life and death Cell Death and Differentiation 6 1043-1053 